\title{
TRADUÇÃO
}

\section{A esperança'}

\section{ROGER TROISFONTAINES}

\author{
Tradução de GENIVAL OLIVEIRA CARVALHO² \\ Revisão de CLAUDINEI APARECIDO DE FREITAS DA SILVA³
}

Numa análise como esta, o método concreto da descrição se revela particularmente precioso. O filósofo não parte de uma definição da qual ele explicitaria progressivamente o conteúdo. Não poderíamos lhe objetar que tudo depende do valor de sua definição inicial e que essa aqui não nos libera necessariamente o real? Ora, ele se esforça, antes de mais nada, em recorrer a uma experiência que ele supõe presente, ao menos em seu estado incoativo, em seus auditores. Que a esperança seja paradoxal, desconcertante por um certo tipo de espíritos, essa não é a questão: não é? Que seja fácil de negá-la em palavra e possível de traí-la ou de pervertê-la efetivamente, é a condição mesma de sua liberdade e, portanto, de seu ser. Esse não é um argumento nem contra sua realidade nem contra seu valor. O eu espero, no entanto, se encontra frequentemente em estado distendido. A descrição do filósofo ajudará talvez aqueles que ela esclarecerá sobre sua experiência pessoal ao atingir um ponto de saturação mais elevado e uma consciência mais pura.

O que chamamos esperança comporta uma degradação que vai da posse “objetiva” à comunhão do ser. É sempre sobre o desabrochamento ou a restauração de uma ordem viva que se dá a esperança. Ela é possível em todo lugar onde a integridade é imperfeita, comprometida, ameaçada. Num sentido mínimo, quando a gente espera recuperar uma coisa perdida, a esperança se une ainda ao restabelecimento de uma certa ordem atualmente conturbada. Nós nos elevamos na qualidade da esperança quando passamos do "ter" à vida e à alma. É legítimo esperar a cura de uma doença ou a volta do filho pródigo. Quanto mais a esperança for pura, mais ela se apoiará, não sobre um "objeto", mais sobre um modo de "ser".

\section{Nem medo, nem desejo}

É certo, porém, que a desconhecemos radicalmente, se a tratamos como um desejo que, para travestir uma realidade "objetiva” que preferimos ignorar, se reveste

\footnotetext{
${ }^{1}$ No original francês: L'espérance, chapitre vi; t. ii, por Roger Troisfontaines, De l'existence à L'être. la Philosophie de Gabriel Marcel. Lettre Préf. de Gabriel Marcel. Louvain: E. Nauwelaerts; Paris: Vrin, 1953, pp. 173-177.

2 Doutor em Ciências da Religião pela PUCSP. E-mail: olgenival@hotmail.com.

3 Pós-Doutorado em Filosofia pela SORBONNE. Professor da UNIOESTE. E-mail: cafsilva@uol.com.br.
} 
de juízos ilusórios. Essa confusão prejudicial é, notoriamente, a de Spinoza e dos sistemas que derivam dele. Uma fórmula tal como: "nec spe nec metu"4 contribui para difundir, para popularizar o erro de perspectiva que situa a esperança no mesmo nível que o medo. Na realidade, se o desejo e o medo se opõem efetivamente no plano do "ter", a esperança se desenvolve numa outra dimensão espiritual, a da salvação. Esta última noção, entretanto, não encontra lugar num universo onde comporta lesões reais; ela seria desprovida de significação em Spinoza ou entre os estoicos. A sua interpretação deficiente se explica, sem dúvida, por isso.

O objeto do "desejo" não é a integridade como tal. É um modo de alegria referida ao "ter", ou melhor ainda, ao "tomar". Desejar é cobiçar: a fortuna, o sucesso, a glória, tal mulher, etc. Diversamente ao desejo, o medo se apoia sobre um modo de sofrer. Sente-se medo de não prosperar, de perder dinheiro, etc. A salvação que visa a esperança não se encontra no nível dessa oposição. É que desejar é sempre desejar "alguma coisa", esperar não é essencialmente "esperar que". O "eu espero que" de nossa linguagem não é um estado diluído da esperança; ele antes constitui uma referência negativa.

"Eu espero que Jacques chegará amanhã para o almoço, e não somente à tarde": isso quer dizer senão que eu o aguardo desejosamente, porque eu tenho esse "desejo" de ver Jacques ficar comigo a maior parte de tempo possível; e tenho razões de pensar que assim será efetivamente: eu sei que ele não pensa em voltar ao seu escritório, pois poderá, enfim, pegar um trem pela manhã, etc. Nós desde já discernimos dois elementos que se encontrarão sempre: o desejo, uma certa crença. Isso, porém, não significa que se trata de um estado diluído, pois, num caso semelhante, eu estou próximo de um ponto de indiferença. Apesar de tudo, não tem tanta importância que Jacques chegue somente às cinco horas. Não há nada aí que me toque verdadeiramente o coração. Em outras palavras, as razões de esperar são aqui exteriores a mim mesmo; elas não estão enraizados no que eu sou. Trata-se, no fundo, de uma simples computação, portanto, acerca das chances que eu deposito "diante" de mim, da solução de um pequeno "problema" prático de probabilidades.

Em contrapartida, se eu acho Jaques chato ou inoportuno, talvez eu diga: eu "me intimido" que ele chegue já para o almoço. Este medo, que se contrapõe ao desejo, não é inteiramente um correlativo negativo da esperança. O contrário do eu espero é o estado de depressão (psicologicamente muito variável) de um indivíduo que não espera nada, nem de si mesmo, nem dos outros, nem da vida. $O$ "derrotismo" que vê as coisas da pior maneira correndo o risco de sempre se degradar em desejo constitui uma ilustração impressionante desse fatalismo pessimista. Este desespero não é, de todo, o medo. Ainda que esse aqui, como o próprio desejo, é ligado a uma espera ansiosa, a desesperança implica, antes, uma

\footnotetext{
4 "Nem medo, nem esperança" (NT).
} 
imobilização da vida que, por assim dizer, se esfria (alguns niilistas contemporâneos pretendem permanecer, complacentemente, neste estado).

\section{Situação: a provação}

As condições de possibilidade da esperança coincidem com as do desespero, mas a reação espiritual é inversa. Do mesmo modo que Bichat definia a vida como o conjunto de forças que lutam contra a morte, pode-se dizer, numa primeira aproximação, que a esperança é uma luta ativa contra o desespero.

Tomado em sua força, o eu espero corresponde a uma provação ora privada, ora comum ao grupo ao qual pertenço. Eu me encontro mergulhado nas trevas inteirores da doença, da separação, do exílio, da servidão, etc.; ora, isso não depende de "mim", ou, em todo caso, de eu escapar-lhe sozinho. Privado da luz à qual eu aspiro, eu provo a horrível impressão de estar no escuro, estregue, sem recursos possíveis. Surge, então, a tentação de eu me deslocar interiormente, de consentir em ser, desde o presente, a coisa descartável que fará de mim, no fim de conta, a doença ou o cativeiro. O desespero coloca como um fato a impotência da realidade. Ele lhe nega a possibilidade de levar em conta, não somente o meu bem, mas ainda o que eu julgo ser o Bem. A esperança é o ato pelo qual um ser orientado para a salvação responde a essa tentação e a triunfa (Esta vitória não acompanha invariavelmente um sentimento de esforço. Este sentimento parece mesmo menos marcado que a esperança mais pura). Assim, o desespero rende-se diante de um fatum, a esperança dá crédito à realidade. Ela (a esperança) afirma que há no ser, para além de tudo o que é "dado", aquilo que pode fornecer a matéria de um inventário ou servir de base à uma computação, um Príncipe misterioso que é conivente comigo, que não pode não querer o que eu quero, se ao menos o que eu quero merece efetivamente ser querido e, de fato, querido inteiramente por mim mesmo. Pelo que parece, ela (a esperança) me dá a intima segurança que a situação intolerável que é presentemente a minha contém uma saída, que há um meio de triunfar o perigo, de crescer na provação. Esperar que o ser que eu amo triunfará sobre o mal considerado incurável que o mina, é dizer: não é possível que eu seja o único a querer sua cura. É impossível que a realidade, em sua profundeza, seja hostil ou somente indiferente àquilo que eu afirmo ser em si um bem. Poderemos eventualmente citar "os exemplos", os "casos" próprios para me desencorajar; para além de toda experiência, de toda probabilidade, de toda estatística, eu afirmo que uma certa ordem será restabelecida, que a realidade está comigo para querer o que seja. Eu não desejo, eu afirmo; a esperança verdadeira tem sempre uma ressonância profética.

Pode-se objetar: "na imensa maioria dos casos, há, contudo, aí, uma ilusão". Voltaremos sobre essa questão. Vejamos, primeiramente, como age a esperança. Ela não implica em nada que eu me sinta forte o suficiente sozinho para curar, por exemplo, um ente querido, converter um pecador, libertar o meu país oprimido. 
Pelo contrário. Para que a minha esperança seja autêntica, é preciso que eu me reconheça de uma certa maneira impotente, atado. A esperança é sempre comandada por uma situação assimilável a de um exílio ou de um cativeiro.

O que implica esta situação? Tal como tantos prisioneiros, durante a última guerra (II) notadamente, eu me parecia cativo ao me encontrar engajado sob um constrangimento exterior num modo de existência que comporta restrições de todas as ordens pelo meu próprio agir. O cativeiro é um sofrer que perdura. Eu me vejo na impossibilidade, não necessariamente de me mover ou mesmo de agir, mas sim de aceder à uma certa plenitude vivida do sentir ou do pensamento. O artista, por exemplo, sofre de uma esterilidade prolongada; ele tem consciência de estar em prisão, ou, se se quiser, no exílio, como se ele estivesse realmente subtraído à luz na qual se encontra normalmente seu ser.

O trágico parece às vezes ausente das situações que favorecem ou suscitam a esperança, assim quando uma mulher espera uma criança ou quando o adolescente se desperta para o amor. A alma, no entanto, experimenta como cativa e se volta para uma luz que ela não vê ainda, para uma luz nascente. Sua noite de espera não poderá perdurar sem se abandonar a tudo que o leva organicamente para uma dissolução (não é deste ponto de vista que se explicam as singularidades, mesmo as aberrações que constatamos frequentemente nos adolescentes ou numa mulher grávida?). O cativeiro participa da alienação. Ao rasgar-se em mim mesmo, porém, ele (o cativeiro) me dá a ocasião de tomar uma consciência mais aguda daquilo do que ela me priva e que eu aspiro agora em reencontrar. Assim, por exemplo, a palavra saúde desperta no doente uma riqueza harmoniosa geralmente insuspeita para o homem perfeitamente sadio.

A esperança não me promete um simples retorno ao status quo, a um simples tornar-se novamente. Ela é inteiramente focada sobre a ligação supra lógica de uma restauração e de uma renovação. Aqueles que têm vivido a experiência do cativeiro numa certa profundidade tiveram o sentimento que ela os preparava em levar uma vida transfigurada onde eles colheriam os frutos espirituais da provação suportada. Esforçando-se em imaginar o que seria a sua vida uma vez libertado, o prisioneiro não a representa como um simples recomeço mecânico de sua existência anterior. Ela deveria ser como essa aqui e, ao mesmo tempo, muito mais, uma promoção extraordinária em relação a ela.

Se a esperança exclui a consideração dos "casos" que seriam de natureza em desencorajar é porque, no mais profundo dela mesmo e sem tomar sempre consciência, ela não se revela no domínio do visível. Quando a esperança se encontra desapontada, iludida (como ocorre frequentemente), a sua dialética ascendente revela que sua essência a situa num plano que transcende todas as negações empíricas. Fundamentalmente, isso não é o sucesso, sob qualquer forma que se apresente, que ela se afirme, é a salvação. Sobre esse plano, ela não podem 
mais abaixo, ser decepcionada. Na verdade, o eu espero envolve a afirmação da eternidade, dos bens eternos.

Não é menos verdade que, para nós, a correlação da esperança e do desespero subsiste até o fim. Eles são inseparáveis. A estrutura do mundo onde vivemos permite e, de algum modo, parece aconselhar um desespero absoluto; mas é num mundo semelhante que surge a esperança invicta. Pode-se reconhecer nos grandes pessimistas da história do pensamento. Eles levaram, ao cabo, uma experiência interior onde a possibilidade radical não deve ser mascarada por nenhuma apologética. Eles nos ajudam a compreender que o desespero pode ser o que fora para Nietzsche (num registro, aliás, infra-ontológico, numa zona semeada de armadilhas mortais): o trampolim da mais alta afirmação. A possibilidade mesma do desespero não manifesta uma grandeza nativa que deve comportar as misteriosas possibilidades de redenção? Não seriam essas as brechas que abre, nossa satisfação, a tentação de desesperar que o espírito de humildade, que o espírito de caridade também, podem penetrar para nos renovar até o mais profundo de nós mesmos?

Submissão: 16.03.2017 / Aceite: 01. 06. 2017 